\title{
Pengembangan Virtual Reality Pengenalan Kendaraan Untuk Anak Usia Dini
}

I Gede Pande Yogianto Sutanaya Jurusan Pendidikan Teknik Informatika Universitas Pendidikan Ganesha, Singaraja Bali

e-mail: pandeyogiex@gmail.com

\author{
I Ketut Resika Arthana \\ Jurusan Pendidikan Teknik Informatika \\ Universitas Pendidikan Ganesha, \\ Singaraja Bali \\ e-mail: resika@undiksha.ac.id
}

\author{
I Made Agus Wirawan \\ Jurusan Pendidikan Teknik Informatika \\ Universitas Pendidikan Ganesha, \\ Singaraja Bali \\ e-mail: imade.aguswirawan@undiksha.ac.id
}

\begin{abstract}
Abstrak-Tujuan dari penelitian ini adalah untuk mengembangkan sebuah aplikasi Virtual Reality Pengenalan Kendaraan Untuk Anak Usia Dini. Adapun tujuan dari pengembangan aplikasi ini adalah untuk membantu proses pembelajaran di TK (Taman Kanak Kanak) dengan tema pengenalan kendaraan. Pengembangan aplikasi ini ditujukan kepada anak-anak TK (Taman Kanak Kanak) agar dapat menarik minat belajar serta mampu menambah wawasan tentang jenis-jenis kendaraan.

Pengembangan aplikasi Virtual Reality Pengenalan Kendaraan Untuk Anak Usia Dini ini menggunakan metode penelitian dan pengembangan (research and development) dengan model yang digunakan yaitu model ADDIE. Model ADDIE terdiri atas lima langkah yang meliputi tahapan 1) Analisis (Analyze), 2) Desain (Design), 3) Pengembangan (Development), 4) Implemetasi (Implementation), 5) Evaluasi (Evaluation). Pada model ini memberikan kesempatan untuk melakukan evaluasi dan revisi secara terus menerus dalam setiap fase yang dilalui, sehingga produk yang dihasilkan menjadi produk yang valid.

Hasil akhir dari projek ini berupa aplikasi virtual reality tentang pengenalan kendaraan untuk anak usia dini yang dapat dipasang pada smartphone android. Aplikasi dapat dimainkan menggunakan bantuan cardboard agar lebih maksimal sehingga objek $3 D$ yang ditampilkan terlihat seolah-olah berada di lingkungan nyata. Hasil pengujian respon pengguna setelah menggunakan aplikasi Virtual Reality Pengenalan Kendaraan Untuk Anak Usia Dini yaitu dengan presentase rata-rata $80 \%$ yang termasuk dalam kriteria sangat baik. Nilai rata-rata $80 \%$ diperoleh dari persentase setiap responden dimana 9 orang menyatakan aplikasi dalam kriteria sangat baik dan 1 orang menyatakan aplikasi dalam kriteria baik. Aplikasi ini dapat dijadikan sebagai media untuk memperkenalkan kendaraan dalam pembelajaran di TK Negeri Pembina Singaraja dengan tema pengenalan kendaraan.
\end{abstract}

Kata Kunci-Virtual Reality, Pengenalan Kendaraan, 3D, Cardboard, Pembelajaran TK.

Abstrack-The purpose of this research was to develop a virtual reality applications of the vehicles introduction for early childhood. There was the purpose of development of this application is to help the learning process in kindergarten with the theme of the introduction of the vehicle. Application development is aimed at kindergarten children in order to attract interest in learning and be able to add the concept about the kinds of vehicle.

The development of virtual reality applications of the vehicle introduction for early childhood using methods of research and development with the model used was ADDIE model. ADDIE models consist of five steps which include stages 1) Analyze, 2) Design, 3) Development, 4) Implementation, 5) Evaluation. On this model provides an opportunity to evaluate and revise continuously in every phase passes, as of the resulting product into a valid product.

The final result of this project in the form of virtual reality applications of the vehicle introduction for early childhood, which can be installed on android smartphone. The application can be played using cardboard for more leverage so that the $3 D$ object is displayed looks as though in the real environment. The test results of the user response after using virtual reality applications of vehicles introduction for early childhood with a percentage of $80 \%$ ratings are very good. The average value of $80 \%$ is obtained from the percentage of each respondent where 9 states in the application criteria very well and one persone stated in the application criteria. This application can be used as a medium to introducing the vehicle in TK Negeri Pembina Singaraja with the vehicles introduction theme.

Keywords-Virtual Reality, Vehicles Introduction, 3D, Cardboard, Kindergarten Learning.

\section{PENDAHULUAN}

Pendidikan taman kanak-kanak atau TK merupakan salah satu jenjang pendidikan untuk anak usia dini yaitu anak yang berusia 4-6 tahun. Pendidikan TK memiliki peran yang sangat penting untuk pengembangan kepribadian anak, serta untuk 
mempersiapkan mereka untuk memasuki jenjang pendidikan selanjutnya. Pembelajaran di TK menggunakan berbagai macam tema. Salah satu tema yang diajarkan yaitu tentang pengenalan kendaraan. Pada pembelajaran di TK tema kendaraan yang diperkenalkan ada 3 jenis yaitu kendaraan udara, kendaraan laut dan kendaraan darat. Saat ini media yang digunakan untuk pembelajaran tersebut hanya menggunakan media gambar.

Berdasarkan hasil wawancara yang dilakukan kepada kepala sekolah TK Negeri Pembina Singaraja mengatakan bahwa media tersebut kurang efektif untuk proses pembelajaran, karena media gambar tidak bisa memberikan informasi yang lebih jelsa mengenai jenis, bentuk, ciri-ciri, dan fungsi dari kendaraan tersebut. Anak-anak TK cenderung merasa bosan dengan pembelajaran yang menggunakan media gambar secara terus-menerus, selain itu apabila mengajak anak-anak untuk melihat kendaraan yang sulit ditemui secara langsung akan memerlukan biaya yang cukup banyak.

Saat ini perkembangan teknologi di bidang smartphone sudah semakin pesat. Sudah banyak jenis permainan atau aplikasi yang mendukung di perangkat smartphone. Setiap harinya ada banyak developer aplikasi yang mengeluarkan jenis permaian atau aplikasi yang terbaru. Salah satu teknologi yang sedang berkembang saat ini yaitu $V R$ atau Virtual Reality. Dalam Virtual Reality ini pengguna akan melihat suatu dunia semu yang sebenarnya adalah gambar-gambar yang bersifat dinamis sehingga pengguna merasa seolah-oleh berada didunia nyata.

Sesuai dengan permasalahan di atas maka peneliti akan merancang sebuah penelitian yang berjudul "Pengembangan Virtual Reality Pengenalan Kendaraan Untuk Anak Usia Dini”" yang mengambil studi kasus di TK Negeri Pembina Singaraja. Dalam pengembangan Virtual Reality ini aplikasi akan dikembangkan dalam versi mobile dan Compatible dengan perangkat Android yang memiliki sensor Gyroscope. Dalam aplikasi ini pengguna dapat melihat secara langsung jenis-jenis kendaraan seperti kendaraan darat, laut, dan udara yang sudah dilengkapi informasi, suara dan animasi. Dengan adanya media tersebut diharapkan dapat memotivasi anak-anak TK dalam mengikuti pembelajaran khususnya yang bertema pengenalan kendaraan.

\section{LANDASAN TEORI}

\section{A. Pendidikan Taman Kanak-Kanak}

Taman kanak-kanak atau TK merupakan jenjang terawal pendidikan formal [1]. Inti pendidikan taman kanak-kanak adalah bermain sambil belajar. Pendidikan untuk anak usia dini sangat penting diberikan agar perkembangan dan penyempurnaan penggunaan pancaindera lebih maksimal.

\section{B. Pembelajaran Dan Tema}

Belajar bagi anak adalah segala sesuatu yang dikerjakannya ketika bermain. Bermain adalah suatu kegiatan yang dilakukan dengan atau tanpa mempergunakan alat yang menghasilkan pengertian atau memberikan informasi, memberi kesenangan maupun mengembangkan imajinasi pada anak [2].

Kurikulum TK pada saat ini mempergunakan tema dalam proses pembelajaran. Tema itu sendiri merupakan alat atau wahana untuk mengenalkan berbagai konsep dan pengetahuan kepada peserta didik secara utuh, sehingga bermakna bagi kehidupannya [3]. Tema ini diterapkan secara bergantian setiap harinya selama semester 1 dan 2 . Tema dalam pembelajaran diberikan dengan maksud untuk menyatukan isi kurikulum dan membuat pembelajaran menjadi lebih bermakna.

\section{Pengenalan Kendaraan}

Pengenalan kendaraan merupakan salah satu tema yang diterapkan pada kurikulum pembelajaran di Taman KanakKanak. Tema kendaraan diberikan pada semester 2 di TK Negeri Pembina Singaraja. Dalam pembelajaran dengan tema kendaraan ada beberapa tahapan yang dilakukan oleh guru pada TK Negeri Pembina Singaraja.

Dalam pembelajaran dengan tema kendaraan guru menggunakan beberapa media antara lain media gambar, dan media yang dibuat oleh guru seperti kerajinan-kerajinan yang terbuat dari barang bekas dan dibentuk menyerupai kendaraan. Selain menggunakan media tersebut guru mencari media yang sesuai di internet.

\section{Kendaraan}

Kendaraan adalah alat yang digunaka sebagai sarana perhubungan untuk mempermudah dan mempercepat manusia dalam mencapai tempat tujuan [4]. Terdapat bermacam-macam kendaraan berdasarkan jenisnya yang akan dikenalkan pada aplikasi ini antara lain: 1) Kendaraan darat meliputi sepeda motor, mobil, truk, bus, delman, dan becak. 2) Kendaraan laut/air meliputi perahu tradisional, kapal penumpang, kapal perang, kapal barang, dan kapal selam. 3) Kendaraan udara meliputi pesawat penumpang, pesawat perang, helikopter, dan pesawat barang/herkules.

\section{E. Virtual Reality}

Virtual Reality adalah teknologi yang membuat pengguna dapat berinteraksi dengan suatu lingkungan yang disimulasikan oleh komputer (komputer-simulated environment) [5].

Lingkungan Virtual Reality terkini umumnya menyajikan pengalaman visual yang ditampilkan pada sebuah layar komputer, tetapi beberapa simulasi virtual reality tingkat tinggi mengikutsertakan juga tambahan informasi hasil pengindraan mata melalui kacamata, suara melalui speaker dan headseat, gerakan tangan melalui glove dan gerakan kaki menggunakan peralatan walker [6]. Adapun penggunaan apliaksi virtual reality dapat dilihat pada Gambar 1 . 


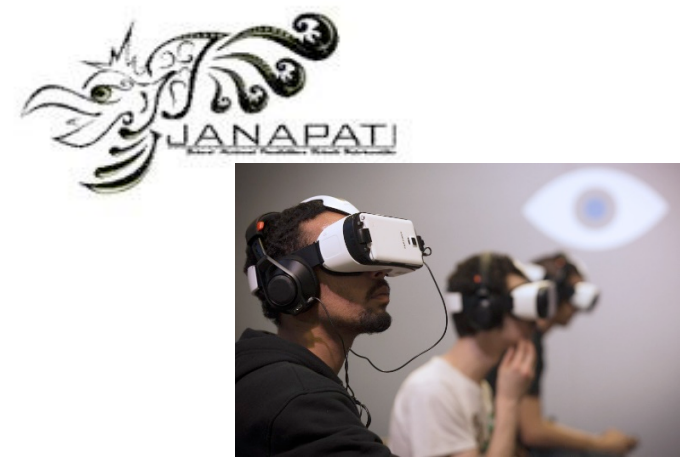

Gambar 1. Penggunaan Aplikasi VR Menggunakan Samsung Gear VR (Sumber: http://theodysseyonline.com/)

\section{F. Cardboard SDK}

Cardboard SDK merupakan SDK atau Software Devlopment Kit yang dapat diintegrasikan dengan Unity sehingga memungkinkan pengguna Unity untuk menciptakan aplikasi $V R$ untuk platform Android dan iOS yang berjalan di google cardboard [7].

Saat ini fitur-fitur yang terdapat pada cardboard SDK sudah semakin bagus dan mudah diterapkan oleh para developer ke dalam aplikasi yang sudah dibuat. Sehingga dengan fitur-fitur terbaru dari cardboard SDK developer dapat berkreasi dan membuat aplikasi yang menarik dan bagus untuk digunakan.

\section{G. Perangkat Lunak Pemodelan 3D}

Software yang digunakan untuk pemodelan object tiga dimensi dalam penelitian ini adalah Blender. Blender adalah software open source yang didedikasikan untuk pemodelan komputer animasi dan penciptaan grafis $3 D$.

Blender digunakan karena memiliki ukuran instalasi yang relatif kecil dan dapat diimplementasikan disemua platform komputer.

\section{H. Unity Game Engine}

Unity Game Engine merupakan software yang digunakan untuk membuat video game $3 D$ atau konten yang interaktif lainnya seperti, visual arsitektur dan real-time $3 D$ animasi.

Unity editor menyediakan beberapa tools untuk mempermudah pengembangan yaitu unity tree dan terrain creator untuk mempermudah pembuatan vegetasi dan terrain serta MonoDevelop untuk proses pemrograman [8].

\section{METODOLOGI}

\section{A. Jenis Penelitian}

Penelitian ini merupakan jenis Penelitian Pengembangan atau Research and Development (R \& D) yakni metode penelitian yang digunakan untuk menghasilkan produk tertentu, dan menguji kefektifan produk tersebut.

\section{B. Model Pengembangan}

Model yang digunakan dalam penelitian pengembangan ini adalah model ADDIE. Model ADDIE merupakan singkatan dari lima tahapan pada model ADDIE itu sendiri antara lain analysis, design, development, implementation, dan evaluation.
p-ISSN 2089-8673 | e-ISSN 2548-4265

Jurnal Nasional Pendidikan Teknik Informatika (JANAPATI)

Volume 6, Nomor 1, Maret 2017

Adapun tahapan dalam model ADDIE dapat dilihat pada Gambar 2.

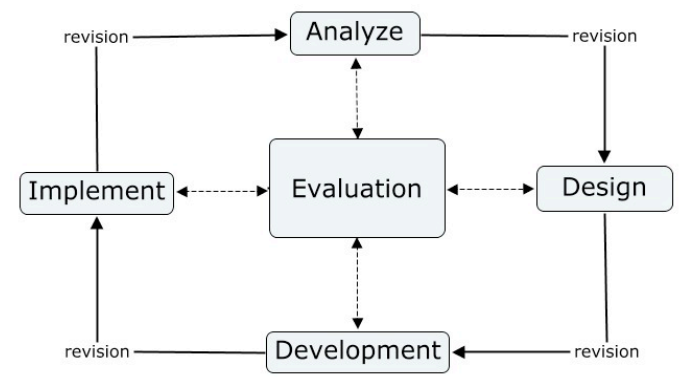

Gambar 2. Tahapan dalam model ADDIE (Sumber: http://educationaltechnology.net)

\section{a) Analysis}

Pada tahap analisis peneliti melakukan identifikasi terhadap masalah-masalah yang ditemukan sehingga dapat dijadikan acuan dalam mengembangkan apliaksi.

1. Kebutuhan Fungsional

Berdasarkan analisis pada pengembangan aplikasi Virtual Reality Pengenalan Kendaraan Untuk Anak Usia Dini, didapatkan kebutuhan fungsional sebagai berikut

a. Aplikasi mampu menampilkan jenis-jenis kendaraan darat, udara, dan laut dalam bentuk $3 D$.

b. Aplikasi mampu memainkan suara dan animasi serta menampilkan informasi kendaraan.

c. Aplikasi dapat dilihat dalam 2 mode yaitu mode $3 D$ dan mode Cardboard.

2. Kebutuhan Non Fungsional.

Berdasarkan analisis pada pengembangan aplikasi Virtual Reality Pengenalan Kendaraan, terdapat beberapa kebutuhan non fungsional yang dibutuhkan :

a. Aplikasi ini dapat berjalan pada sistem operasi Android minimal versi 4.1 .1 (Jelly Bean) dan memiliki sensor gyroscope.

b. Apliasi memiliki tampilan yang user friendly, tujuannya agar pengguna merasa tertarik dan lebih mudah dalam menggunakan aplikasi.

c. Aplikasi dapat mengikuti pergerakan smartphone.

\section{b) Design}

1. Use Case Diagram

Use case diagram merupakan diagram yang menggambarkan aksi-aksi yang dapat dilakukan oleh aktor sesuai dengan hasil identifikasi kebutuhan pengguna. Adapun use case diagram aplikasi virtual reality pengenalan kendaraan untuk anak usia dini dapat dilihat pada Gambar 3. 


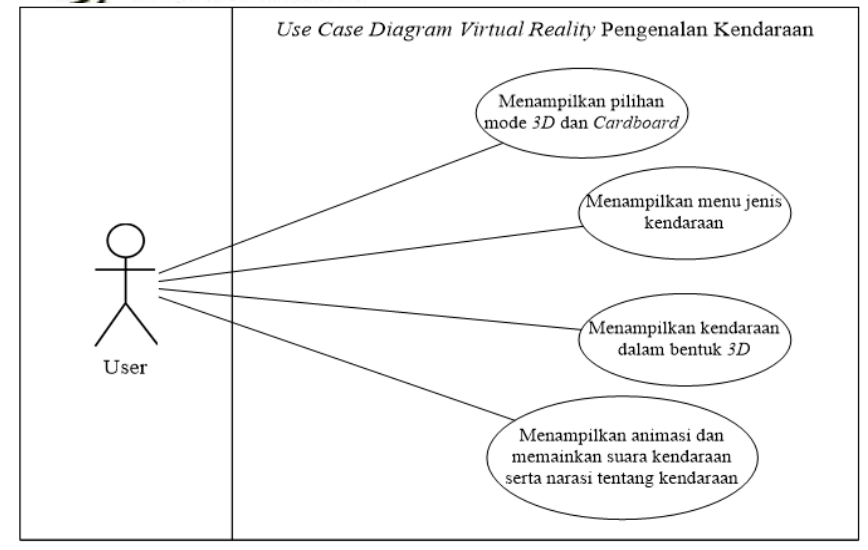

Gambar 3. Use Case Diagram

\section{Activity Diagram}

Activity diagram menggambarkan berbagai alur aktivitas dalam sistem yang sedang dirancang, bagaimana masingmasing alur berawal, decision yang mungkin terjadi, dan bagaimana mereka berakhir. Adapun activity diagram aplikasi virtual reality pengenalan kendaraan untuk anak usia dini dilihat pada Gambar 4.

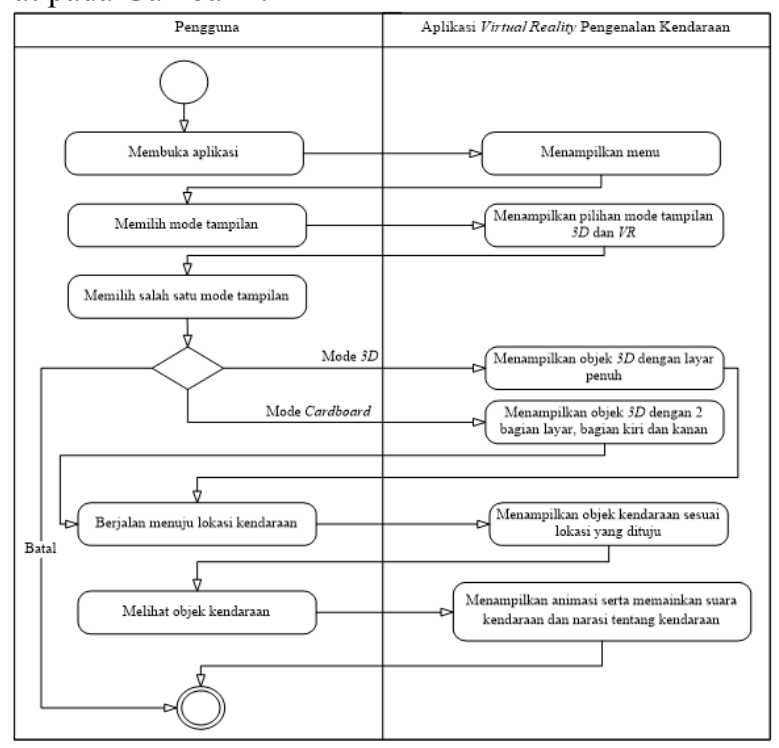

Gambar 4. Activity Diagram

\section{c) Development}

Pada tahapan pengembangan, rancangan yang telah dibuat sebelumnya diimplementasikan dengan perangkat lunak yang telah disesuaikan. Langkah awal dilakukan pembentukan $3 D$ objek dengan tahapan modelling, texturing, ringging, skining, animation, lighting sesuai yang sudah direncanakan pada tahap pra produksi. Berikut kebutuhan perangkat lunak dan perangkat keras yang digunakan dalam pengembangan aplikasi.

1) Kebutuhan Perangkat Lunak

Berdasarkan analisis kebutuhan yang dilakukan, adapun perangkat lunak yang dibutuhkan dalam pengembangan aplikasi Virtual Reality Pengenalan Kendaraan Untuk Anak Usia Dini adalah sebagai berikut.

a. Unity 5.1 digunakan sebagai editor dalam pengembangan Aplikasi Virtual Reality.

b. Blender 2.73 digunakan dalam membuat Objek $3 D$.

c. Cardboard SDK sebagai Library SDK unruk membangun Aplikasi Virtual Reality.

d. Adobe Photoshop CS6 digunakan untuk membuat texture.

e. SDK GoogleVRForUnity digunakan untuk menampilkan fitur-fitur $V R$ pada smartphone

f. .Audacity 2.1.0 digunakan untuk mengedit audio pada aplikasi.

2) Kebutuhan Perangkat Keras

Aplikasi Virtual Reality Pengenalan Kendaraan Untuk Anak Usia Dini akan dikembangkan dengan perangkat keras laptop dan smartphone sebagai berikut:

a. Perangkat Komputer

1. Laptop ASUS X450EA

2. Processor AMD E1-2500APU@1.4 GHz

3. $R A M 2 G B$

4. $H D D 500 G B$

5. Dilengkapi alat input dan output

b. Perangkat Smartphone

1. Smartphone Xiaomi Redmi Note 3

2. Resolusi $1080 \times 1920$ pixels

3. Processor Octa-core $2.0 \mathrm{GHz}$

4. RAM $3 G B$

5. Kamera $13 \mathrm{MP}$

\section{d) Implementation}

Pada tahap ini peneliti akan melakukan implementasi aplikasi di TK Negeri Pembina Singaraja. Aplikasi akan diterapkan saat pembelajraan dengan tema kendaraan. Adapun tahapan implementasi aplikasi dapat dilihat pada Tabel 1.

Tabel 1. Tahapan Implementasi Aplikasi

\begin{tabular}{|c|l|}
\hline Tahap & \multicolumn{3}{|c|}{ Penjelasan } \\
\hline 1 & $\begin{array}{l}\text { Peneliti memperkenalkan aplikasi Virtual } \\
\text { Reality Pengenalan Kendaraan kepada } \\
\text { guru pengajar di TK Negeri Pembina } \\
\text { Singaraja. }\end{array}$ \\
\hline 2 & $\begin{array}{l}\text { Peneliti menjelaskan tata cara } \\
\text { menggunakan aplikasi Virtual Reality } \\
\text { Pengenalan Kendaraan mulai dari } \\
\text { membuka aplikasi, memilih mode } \\
\text { tampilan, pemasangan smartphone pada } \\
\text { cardboard, memilih jenis kendaraan, dan } \\
\text { cara melihat objek beserta informasinya. }\end{array}$ \\
\hline 3 & $\begin{array}{l}\text { Guru mengenalkan kendaraan } \\
\text { menggunakan aplikasi Virtual Reality } \\
\text { Pengenalan Kendaraan kepada anak-anak. }\end{array}$ \\
\hline 4 & $\begin{array}{l}\text { Guru mendampingi ketika anak-anak } \\
\text { menggunakan aplikasi Virtual Reality } \\
\text { Pengenalan Kendaraan. }\end{array}$ \\
\hline
\end{tabular}




\section{e) Evaluation}

Selanjutnya pada tahap evalusi Jenis pengujian yang akan digunakan adalah Uji Blackbox, Uji Whitebox, Uji Ahli Media, Uji Ahli Isi, Uji Respon Pengguna dan Uji UX (User Experience).

Tujuan dari pengujian apliaksi yaitu untuk mengetahui kekurangan dan kelemahan maupun kesalahan (error) dari aplikasi yang dikembangkan, sehingga aplikasi masih bisa diperbaiki untuk mengurangi kesalahan-kesalahan yang terjadi sebelum diimplementasikan ke masyarakat luas.

Pengujian black box, ahli isi, ahli media, dan respon pengguna menggunakan angket dengan beberapa butir pernyataan. Adapun bobot pernyataan pada angket dapat dilihat pada Tabel 2.

Tabel 2. Bobot Pernyataan

\begin{tabular}{|l|c|c|c|c|c|}
\hline Pernyataan & STS & TS & CS & S & SS \\
\hline Positif & 1 & 2 & 3 & 4 & 5 \\
\hline Negatif & 5 & 4 & 3 & 2 & 1 \\
\hline
\end{tabular}

\section{Keterangan:}

SS $\quad=$ Sangat Setuju

$\mathrm{S} \quad=$ Setuju

CS $\quad=$ Cukup Setuju

TS $\quad=$ Tidak Setuju

STS $\quad=$ Sangat Tidak Setuju

Setelah melakukan perhitungan terhadap angket yang telah diberikan penilaian, maka kriteria penilaian dari nilai yang didapat dapat dijabarkan sebagai berikut.

1. Angka $0 \% \quad-19,99 \%=$ Sangat (tidak Setuju/buruk/kurang sekali)

2. Angka 20\% - 39,99\% = Tidak setuju / Kurang baik)

3. Angka $40 \%-59,99 \%=$ Cukup $/$ Netral

4. Angka $60 \%-79,99 \%=($ Setuju/Baik/suka $)$

5. Angka $80 \%-100 \%=$ Sangat $($ Setuju/Baik/Suka)

\section{HASIL DAN PEMBAHASAN}

\section{A. Hasil Penelitian}

Hasil penelitian yang telah dilakukan adalah sebuah aplikasi yang dapat dijalankan pada perangkat smartphone android yang dilengkapi dengan sensor gyroscope. Adapun hasil pengembangan apliaksi virtual reality pengenalan kendaraan untuk anak usia dini dapat dilihat pada Gambar berikut.

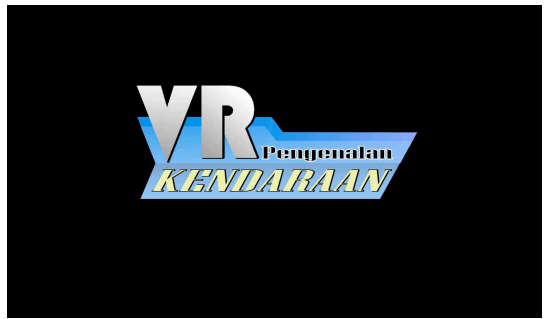

Gambar 5. Implementasi Splash Screen
Pada gambar 5 merupakan tampilan dari splash screen dari aplikasi VR Pengenalan Kendaraan. Tampilan splash screen akan muncul saat menjalankan apliaksi $V R$ Pengenalan Kendaraan.

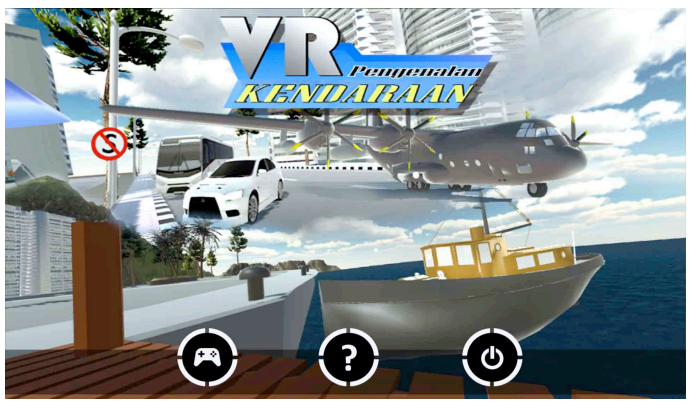

Gambar 6. Implementasi Menu Utama

Pada gambar 6 menunjukan tampilan menu utama aplikasi $V R$ Pengenalan Kendaraan. Pada menu utama terdapat 3 tombol yaitu tombol mulai, bantuan, dan keluar.

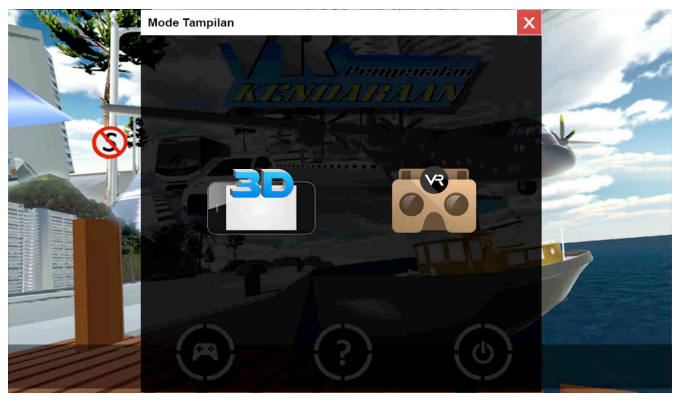

Gambar 7. Implementasi Pilihan Mode

Gambar 7 menunjukan tampilan pilihan mode. Dimana pada pilihan mode terdapat 2 pilihana yaitu mode $3 D$ dan mode $V R$.

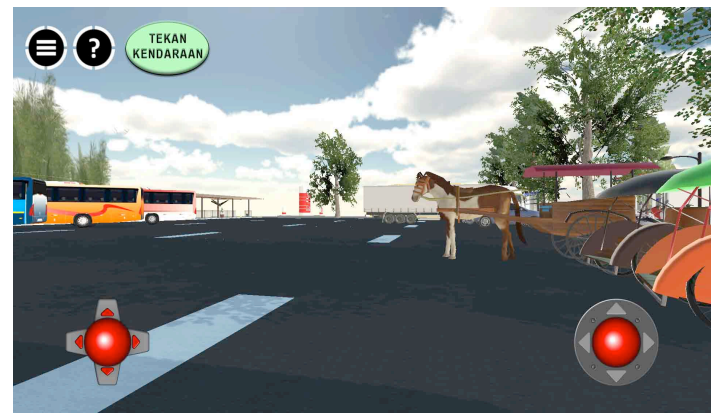

Gambar 8. Implementasi Pengenalan Kendaraan Dalam Mode $3 D$

Pada gambar 8 menunjukan tampilan utama aplikasi $V R$ Pengenalan Kendaraan. Dimana pada tampilan utama terdapat 2 buah joystick dsebelah kanan dan kiri bawah serta terdapat 2 buah menu pada bagian kiri atas. 


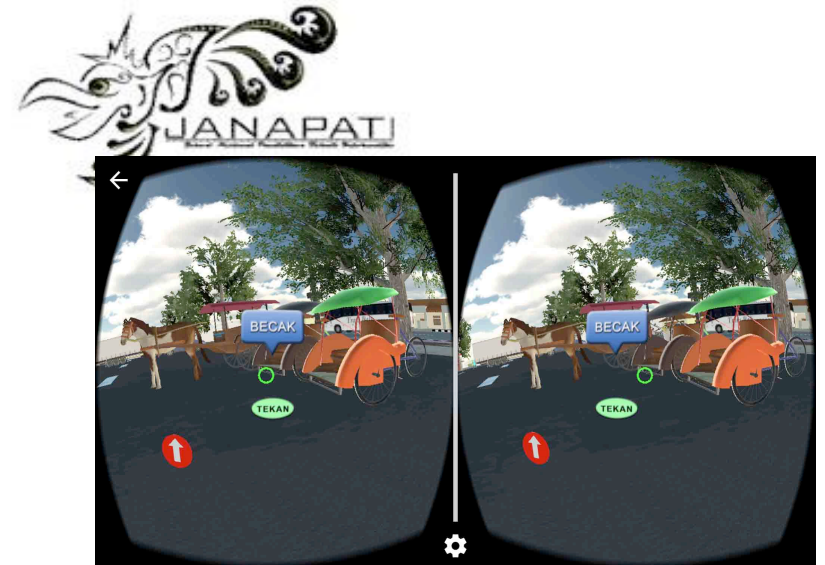

Gambar 9. Implementasi Pengenalan Kendaraan Dalam Mode $V R$

Pada gambar 9 menunukan tampilan utama mode $V R$. Dimana pada tampilan utaman mode $V R$ terdapat 1 buah menu apabila melihat keatas dan terdapat pula 1 buah penanda jika dalam kedaraan berjalan atau berhenti.

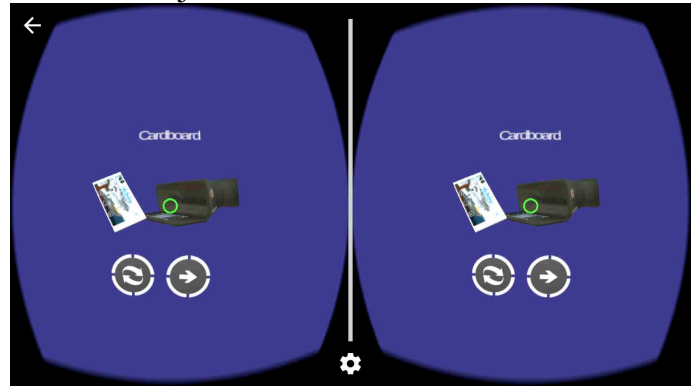

Gambar 10. Implementasi Bantuan Aplikasi Dalam Mode $V R$

Pada gambar 10 menunjukan tampilan bantuan penggunaan dalam mode $V R$. Pada gamabr 10 terdapat 2 buah tombol yaitu tombol refresh dan tombol kembali.

Sebelum digunakan oleh pengguna maka aplikasi akan diujikan terlebih dahulu untuk memastikan bahwa aplikasi sudah berjalan dengan baik dari awal sampai akhir proses serta tidak terjadi kesalahan atau error. Pengujian yang dilakukan yaitu pengujian black box untuk mengetahui kebenaran dan kesesuaian proses apliaksi serta penggunaan aplikasi pada beberapa smartphone android yang berbeda, selanjutnya pengujian ahli isi, pengujian ahli media, dan yang terakhir yaitu pengujian respon pengguna serta pengujian UX (User Experience) dengan metode UEQ.

\section{1) Uji Black Box}

Pelaksanaan uji kasus untuk pengujian black box dapat dilaksanakan beberapa butir kasus uji

a) Uji Kebenaran Proses

Pada pengujian kasus uji 1 memiliki tujuan untuk menguji kebenaran proses aplikasi Virtual Reality Pengenalan Kendaraan Untuk Anak Usia Dini sesuai dengan target pencapaian. Pada tahap ini uji coba pengujian aplikasi akan diberikan angket setelah menggunakan aplikasi. Pengujian uji kasus 1 dilakukan oleh 5 orang mahasiswa. Pada kasus uji 1 dilaksanakan pada 11 November 2016. Semua proses dimulai dari saat pertama kali aplikasi dijalankan sampai dengan
p-ISSN 2089-8673 | e-ISSN 2548-4265

Jurnal Nasional Pendidikan Teknik Informatika (JANAPATI)

Volume 6, Nomor 1, Maret 2017

selesai keluar dari aplikasi berfungsi dengan baik. Pelaksanaan kasus uji 1 mendapat kriteria sangat baik yaitu dengan perolehan nilai rata-rata $100 \%$.

b) Uji Pada 5 Smartphone Berbeda

Pada pengujian kasus uji 2 dilakukan untuk mengetahui apakah aplikasi yang dibuat sudah berjalan dengan baik pada perangkat smartphone yang berbeda mulai dari proses instalasi hingga saat aplikasi dijalankan. Pada tahap ini uji coba pengujian aplikasi akan diberikan angket setelah menggunakan aplikasi Virtual Reality Pengenalan Kendaraan Untuk Anak Usia Dini. Pengujian uji kasus 2 dilakukan oleh lima orang mahasiswa. Pada kasus uji 2 dilaksanakan pada 11 Agustus 2016. Pengujian kasus uji 2 dilakukan pada 5 jenis smartphone yang berbeda yaitu smartphone Xiaomi Redmi 3, Vivo Y31, Asus Zenfone 2 ZE551ML, Oppo A37 dan Lenovo K4 Note. Pelaksanaan kasus uji 2 mendapat kriteria sangat baik dengan perolehan nilai rata-rata $100 \%$.

\section{2) Uji Ahli Isi}

Pengujian terhadap ahli isi dilakukan pada tanggal 17 dan 18 november 2016 dengan 2 orang ahli isi yaitu Ibu Mutiara Magta, M.Pd yang merupakan dosen di Jurusan PGPAUD Undiksha. Kemudian yang kedua yaitu Ibu Ni Komang Erliawati, S.Pd.,Aud yang merupakan guru di TK Negeri Pembina Singaraja.

Berdasarkan penilaian dari ahli isi Ibu Mutiara Magta, M.Pd diperoleh nilai 84\% dan dari Ibu Ni Komang Erliawati, S.Pd.,Aud diperoleh nilai $100 \%$, dapat dianalisis presentase keseluruhan penilaian yaitu 92\%. Aplikasi Virtual Reality Pengenalan Kendaraan Untuk Anak Usia Dini berada dalam kriteria sangat baik dengan presentase penilaian $92 \%$.

Aplikasi yang diberikan penilaian sudah mendapat validasi kelayakan uji coba lapangan dan ada sedikit saran yang diberikan oleh Ibu Mutiara Magta, M.Pd yaitu untuk kedepannya agar menambahkan objek kendaraan yang ada di Bali.

\section{3) Uji Alhi Media}

Pengujian ahli media dilakukan oleh 2 orang ahli media yaitu Bapak I Ketut Purnamawan, S.Kom.,M.Kom yang merupakan dosen di Jurusan D3 Manajemen Informatika Undiksha, pada tanggal 10 November 2016. Penguji media yang kedua adalah Bapak I Made Putrama, ST.,M.Tech merupakan dosen di Jurusan Pendidikan Teknik Informatika Undiksha, pada tanggal 17 November 2016.

Berdasarkan penilaian dari ahli media Bapak I Ketut Purnamawan, S.Kom.,M.Kom diperoleh nilai 96\% dan dari Bapak I Made Putrama, ST.,M.Tech diperoleh nilai 85\%, dapat dianalisa presentase keseluruhan penilaian yaitu 91\%. Aplikasi Virtual Reality Pengenalan Kendaraan Untuk Anak Usia Dini sangat baik dengan presentase pencapaian aplikasi dari kesesuaian audio berada dalam kriteria sangat baik dengan presentase penilaian $83 \%$, dari segi kesesuain visual berada dalam kriteria sangat baik dengan presentase penilaian $90 \%$, 
dan segi penggunaan berada dalam kriteria sangat baik dengan presentase penilaian $100 \%$.

Revisi media dilakukan setelah mendapatkan saran perbaikan dari ahli media Bapak I Made Putrama, ST.,M.Tech. Ada beberapa bagian dari apliaksi yang disarankan untuk diperbaiki agar aplikasi menjadi lebih baik lagi. Aplikasi yang sudah direvisi kemudian diperlihatkan kembali untuk diberikan penilaian ulang dan validasi kelayakan uji lapangan.

\section{4) Uji Respon Pengguna}

Uji respon pengguna dilakukan mulai dari hari kamis, 24 november 2016 sampai dengan selasa, 29 november 2016 dengan melibatkan sepuluh orang anak-anak TK Negeri Pembina Singaraja. Pengujian dilakukan dengan mempersilahkan anak-anak untuk mencoba menggunakan aplikasi Virtual Reality Pengenalan Kendaraan Untuk Anak Usia Dini dengan didampingi oleh pengembang aplikasi dan guru pengajar kemudian dilanjutkan dengan pemberian angket dimana guru yang menanyakan langsung kepada anak-anak dan langsung mengisi angket sesuai dengan pendapat anakanak.

Berdasarkan hasil analisis uji respon pengguna diketahui bahwa rerata presentase keseluruhan dari 10 orang responden dengan 6 butir penilaian yaitu 80\%. Aplikasi masuk dalam kriteria sangat baik. Hasil perhitungan respon pengguna dapat diketahui bahwa dari 5 kriteria penilaian pada tiap butir soal, 9 orang pengguna menyatakan aplikasi Virtual Reality Pengenalan Kendaraan Untuk Anak Usia Dini dalam kriteria sangat baik, dan 1 orang pengguna menyatakan aplikasi Virtual Reality Pengenalan Kendaraan Untuk Anak Usia Dini dalam kriteria baik.

\section{5) Uji UX (User Experience) Dengan Metode UEQ (User Experience Quistionneir)}

Uji UX dilakukan terhadap 10 orang anak-anak TK Negeri Pembina Singaraja, dimana angket UEQ diisikan oleh guru berdasarkan pendapat dari anak-anak setelah menggunakan aplikasi Virtual Reality Pengenalan Kendaraan Untuk Anak Usia Dini. Uji UX dilakukan mulai dari hari kamis, 24 november 2016 sampai selasa, 29 november 2016.

Proses analisis data dilakukan dengan menggunakan program UEQ Data Analysis Tool yang bersumber dari www.ueq-online.org. Berdasarkan perhitungan dengan program UEQ Data Analysis Tool, hasil yang diperoleh menunjukan nilai yang baik dari masing-masing scale. Adapun hasil yang diperoleh dirangkum pada Tabel 3 .

Tabel 3. Skala UEQ

\begin{tabular}{|lcl|}
\multicolumn{1}{c}{ Scale } & Mean & $\begin{array}{c}\text { Comparisson to } \\
\text { benchmark }\end{array}$ \\
\hline Daya Tarik & 2 & Excellent \\
Kejelasan & 1.575 & Good \\
Efisiensi & 1.625 & Good \\
Ketepatan & 1.725 & Excellent
\end{tabular}

\begin{tabular}{|lcl|}
\hline Scale & Mean & $\begin{array}{c}\text { Comparisson to } \\
\text { benchmark }\end{array}$ \\
\hline Stimulasi & 1.7 & Excellent \\
Kebaruan & 1.6 & Excellent \\
\hline
\end{tabular}

Dari 6 komponen penilaian berdasarkan program $U E Q$ Data Analysis Tool, daya tarik memperoleh nilai 2 yaitu sangat baik, kejelasan dengan nilai 1.575 yaitu baik, efisiensi dengan nilai 1.625 yaitu baik, ketepatan dengan nilai 1.725 yaitu sangat baik, stimulasi dengan nilai 1.7 yaitu sangat baik, dan kebaruan dengan nilai 1.6 yaitu sangat baik. Semua komponen tersebut menggunakan nilai standar yang berbeda untuk menentukan kriteria nilai (Exellent, Good, Above Average, Below Average, Bad). Dari hasil pada tabel dapat divisualisasikan menggunakn garfik seperti pada Gambar 11.

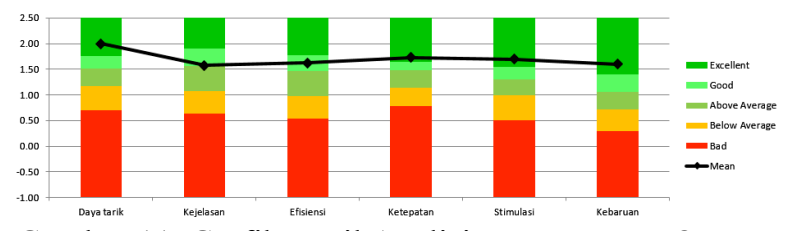

Gambar 11. Grafik Hasil Analisis Program UEQ Data Analysis Tool

\section{SIMPULAN}

Berdasarkan hasil analisis, implementasi dan pengujian pada penelitian pengembangan aplikasi Virtual Reality Pengenalan Kendaraan Untuk Anak Usia Dini dapat ditarik kesimpulan sebagai berikut.

1. Rancangan Aplikasi Virtual Reality Pengenalan Kendaraan Untuk Anak Usia Dini menggunakan metode penelitian pengembangan R\&D (research and development). Model yang dijadikan acuan dalam penelitian pengembangan ini adalah Model ADDIE. Adapun tahapan dalam model ADDIE yaitu Analysis (analisis), Design (desain), Development (pengembangan), Implementation (implementasi), dan Evaluation (evaluasi).

2. Implementasi Aplikasi Virtual Reality Pengenalan Kendaraan Untuk Anak Usia Dini berupa sebuah aplikasi yang berisikan tentang pengenalan kendaraan yang diberikan untuk anak usia dini. Aplikasi Virtual Reality Pengenalan Kendaraan Untuk Anak Usia Dini mampu dimainkan menggunakan cardboard sehingga anak-anak dapat berinteraksi dengan lingkungan virtual reality seakan-akan berada di dunia nyata.

3. Berdasarkan hasil pengujian aplikasi Virtual Reality Pengenalan Kendaraan Untuk Anak Usia Dini mendapatkan respon yang positif dari pengguna. Hasil pengujian untuk mengetahui respon pengguna setelah menggunakan aplikasi Virtual Reality Pengenalan Kendaraan Untuk Anak Usia Dini dengan presentase penilaian $80 \%$ yaitu sangat baik. 
[1] Widodo, Sunu. (1998). Riang Berdendang. Yogyakarta: Kanisius.

[2] Sudono, Anggani. (2000). Sumber Belajar Dan Alat Permainan. Jakarta: PT. Grasindo.

[3] Suyanto, Asep Jihad. (2013). Menjadi Guru Profesional. Jakarta: Esensi

[4] Untoro, Joko. (2010). Buku Pintar Pelajaran. Jakarta: Wahyumedia.

[5] Anna. (2008). Implementasi Obyek 3D Virtual Reality Pada Aplikasi Bersepeda Di UI Berbasis 3D Gamestudio. Tersedia pada http://lib.ui.ac.id/file?file=digital/20248856R0308127.pdf (diakses pada tanggal 24 Januari 2016).

[6] Suwarto. (2014). Desain Dan Implementasi Virtual Reality 3D Perpustakaan Universitas Brawijaya. Tersedia pada http://filkom.ub.ac.id/doro/download/article/file/DR0009 1201412 (diakses pada tanggal 20 Februari 2016).

[7] Cardboard SDK untuk Unity. (2015, September 09). Diambil kembali dari Google Devlopers: https://devlopers.google.com/Cardboard/Unity/?hl=id\#fit ur (diakses pada tanggal 23 Maret 2016).

[8] Berta. (2013). Pembuatan Aplikasi 3D Viewer Mobile dengan Menggunakan Teknologi Virtual Reality (Studi Kasus: Perobekan Bendera Belanda di Hotel Majapahit). Tersedia pada http://ejurnal.its.ac.id/index.php/teknik/article/viewFile/4 662/1128 (diakses pada tanggal 18 Februari 2016). 